\title{
ESD with double-balloon endoluminal intervention platform versus standard ESD for management of colon polyps $\square$
}

\author{
Authors \\ Sharon John' ${ }^{1}$, Chandra Kovvali ${ }^{1}$, Mohamed O. Othman ${ }^{1,4}$ \\ Institutions \\ 1 Division of Gastroenterology, Baylor College of \\ Medicine, Houston, Texas \\ 2 Department of Internal medicine, Gastroenterology \& \\ Hepatology, Ain Shams University, Cairo, Egypt \\ 3 Department of Medicine, Baylor College of Medicine, \\ Houston, Texas \\ 4 Baylor St Luke's Medical Center, Houston, Texas
}

Mohamed Saleh Ismail ${ }^{1,2}$, Firas Bahdi ${ }^{3}$, Michael Oliver Mercado ${ }^{1}$, Randa Habazi ${ }^{1}$, Angel Alexander ${ }^{1}$, Sahana Prabhu ${ }^{1}$,

submitted 6.5.2020

accepted after revision 29.6.2020

\author{
Bibliography \\ Endoscopy International Open 2020; 08: E1273-E1279 \\ DOI 10.1055/a-1226-6372 \\ ISSN 2364-3722 \\ (c) 2020. The Author(s).
}

This is an open access article published by Thieme under the terms of the Creative Commons Attribution-NonDerivative-NonCommercial License, permitting copying and reproduction so long as the original work is given appropriate credit. Contents may not be used for commecial purposes, or adapted, remixed, transformed or built upon. (https://creativecommons.org/licenses/by-nc-nd/4.0/)

Corresponding author

Mohamed Othman, MD, Chief of Gastroenterology Section, Baylor St. Luke's Medical Center, William T. Butler Endowed Chair for Distinguished Faculty, Associate Professor of Medicine, Baylor College of Medicine, 7200 Cambridge St., 8th Floor, Suite 8B, Houston, Texas 77030, United States Fax: +1-8329982866

mohamed.othman@bcm.edu

\section{ABSTRACT}

Background and study aims Endoscopic submucosal dissection (ESD) with the double-balloon endoluminal inter- vention platform (DEIP) is a novel technique for removal of complex colon polyps $(>2 \mathrm{~cm}$ ) or those located in anatomically difficult positions. DEIP helps create a therapeutic zone with improved visualization and stability, facilitating polyp removal. We aimed to compare the outcomes of DEIP with the conventional cap-assisted ESD (standard ESD) technique for colon polyp resection, in particular, the ability to complete the ESD procedure without resorting to hybrid ESD or piecemeal resection.

Patients and methods This was a retrospective cohort of all patients who underwent colon ESD in a single large tertiary referral center between September 2016 and October 2019. Information was collected on patient demographics and study outcomes including procedure time, rates of en bloc and curative resection, operative and postoperative complications. All patients were followed up for 1 month after the procedure.

Results 111 patients were included in the study (DEIP 60, standard ESD 51). There was no statistically significant difference between mean procedures time $( \pm S D)$ in the two groups, mean $(81.9 \pm 35.4$ min standard vs. $96.4 \pm 42.2 \mathrm{~min}$ in DEIP). Mean polyp size $( \pm S D)$ was similar between the two groups $\left(7.6 \pm 6.0 \mathrm{~cm}^{2}\right.$ vs. $\left.6.2 \pm 5.5 \mathrm{~cm}^{2}, P=.2\right)$. There were no significant differences in en bloc and curative resection rates or operative and postoperative complications between the two techniques.

Conclusion Procedure time was similar using both techniques. However, DEIP enabled the entire procedure to be performed using the ESD technique without resorting to snare resection, which may affect the en bloc and curative resection rate. There were no significant differences in en bloc and curative resection rates between the two groups, probably due to the small sample size.

\section{Introduction}

Endoscopic submucosal dissection (ESD) has emerged as a widely accepted treatment for complex colon lesions, particularly lesions $>20 \mathrm{~mm}$ or those located in anatomically difficult positions [1]. Resection of complex colon polyps is technically challenging and time consuming. ESD is superior to endoscopic mucosal resection (EMR) in managing complex colon polyps with higher en bloc and curative resection rates and a lower recurrence rate [2]. However, widespread adoption of ESD is limited due to the long procedure time, technical difficulty, lack of 
training facilities, and higher risk of perforation [3,4]. To expedite dissection, hybrid ESD was introduced as a rescue treatment modality in difficult ESD cases [5]. Hybrid ESD is defined as circumferential mucosal incision and partial submucosal dissection with use of a snare for the final resection step. It has the advantage of shorter procedure time. However, the en bloc resection rate is lower than with standard ESD [6].

Cap-assisted ESD (ESD) is considered the standard ESD technique, where the transparent cap assists in better visualization by keeping distance between the endoscope end and target lesion [7]. Introduction of ESD with the double-balloon endolumenal intervention platform (DEIP) has been proposed to facilitate technically demanding ESD procedures and reduce dissection time [8]. DEIP has no relationship to the double-balloon enteroscopy. DEIP is an add-on device to the endoscope. It comprises a flexible oversheath with two manually inflatable balloons ( Fig. 1, \ Fig. 2). The double-balloon endoluminal intervention device stabilizes the colon and creates a therapeutic zone to ensure sufficient submucosal dissection. In addition, the fore balloon can be used to create traction using a suture and clip, which can further expedite the dissection process ( Fig. 3, > Fig.4) [9]. However, the DEIP technique is in its early adoption stages and has only been described in a case report and a small case series of porcine models $[8,10]$. Beside its use in ESD, DEIP can be used in patients with a long and tortuous colon, as it can reduce sigmoid looping and shorten the colon. This improves the reach and control during complex polypectomy procedures.

We undertook this study with two key objectives: 1) to compare en bloc resection rate and procedure time between standard ESD and DEIP; and 2) to compare the ability to complete the ESD procedure without resorting to hybrid ESD or piecemeal resection in standard ESD and DEIP.

\section{Patients and methods}

\section{Study design and patient population}

The study was approved by the Institutional Review Board of Baylor College of Medicine, Houston, Texas. This study included all patients who underwent colon ESD at Baylor St Luke's Medical Center, Houston, Texas, United States between September 2016 and October 2019. Patients were referred to our center for management of colonic polyps that were found to be: 1) impossible to resect using the en bloc method; 2) located in an anatomically challenging position; 3 ) fibrotic or to have a central depression; or 4) to be residual after prior EMR.

\section{ESD procedures}

All ESD procedures were carried out by a single experienced endoscopist (M.O.), using a single-channel video endoscope with water jet function Pentax EC38-i10L (Pentax America, Montvale, New Jersey, United States). M.O. started performing ESD in 2014 and had performed more than 500 ESDs at the time of writing this manuscript. DEIP became available in our center in September 2017, and all colon ESDs done prior to that time were performed using a standard ESD approach (18 lesions). Training using the DEIP was completed by performing

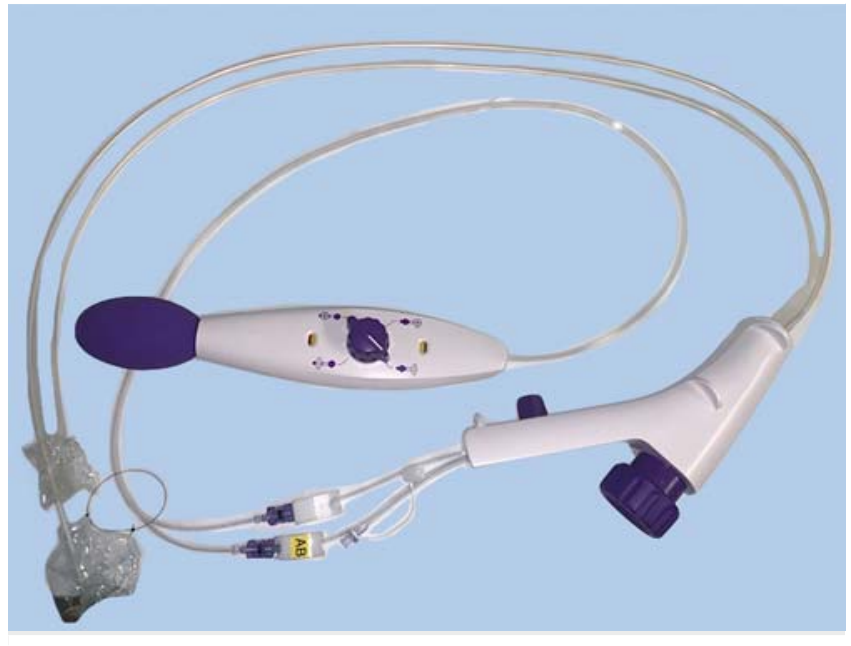

Fig. 1 Double-balloon endoluminal intervention platform (DEIP).

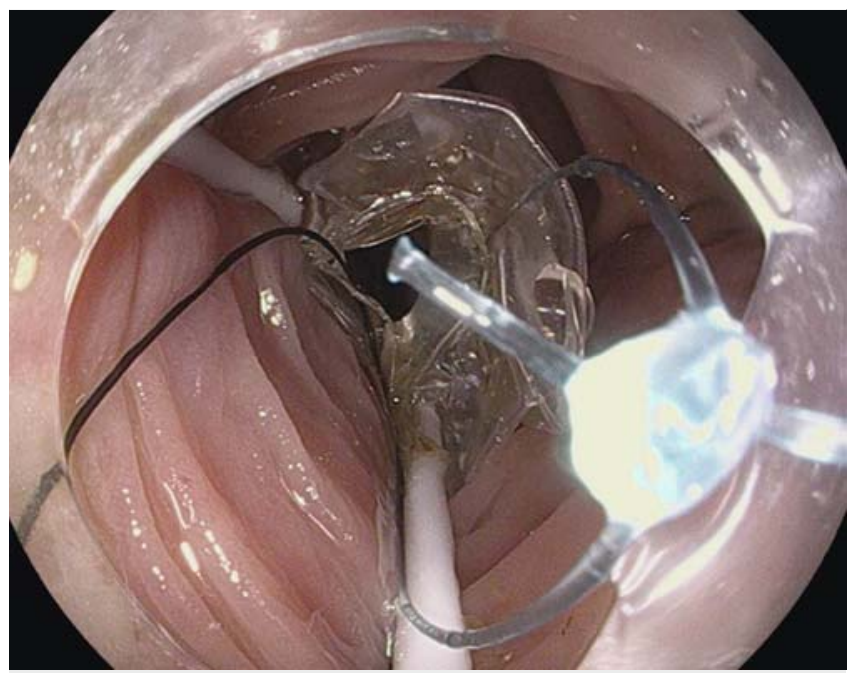

Fig. 2 Endoscopic view of the fore-balloon part of DEIP.

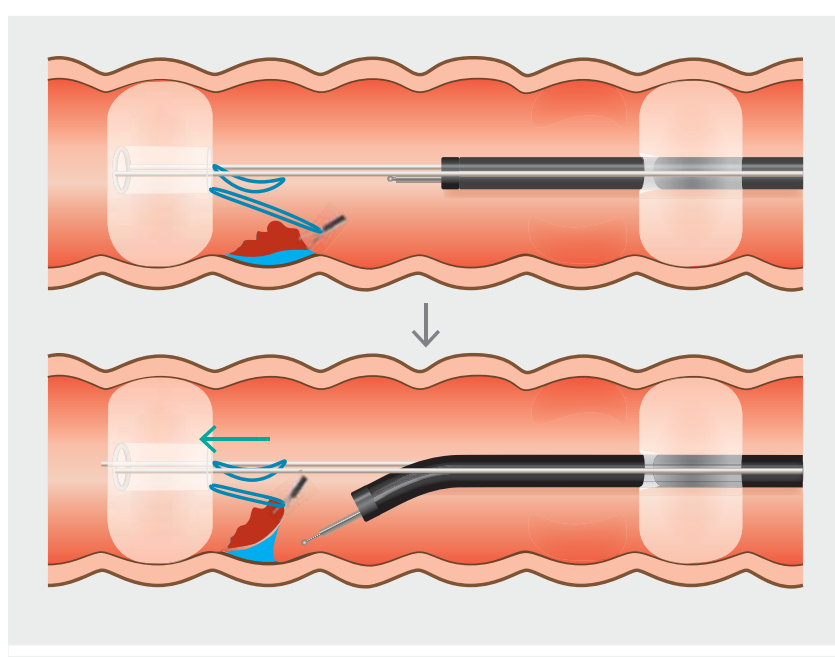

- Fig. 3 Diagram explaining the concept of dynamic retraction using the fore balloon, suture, and a clip. 


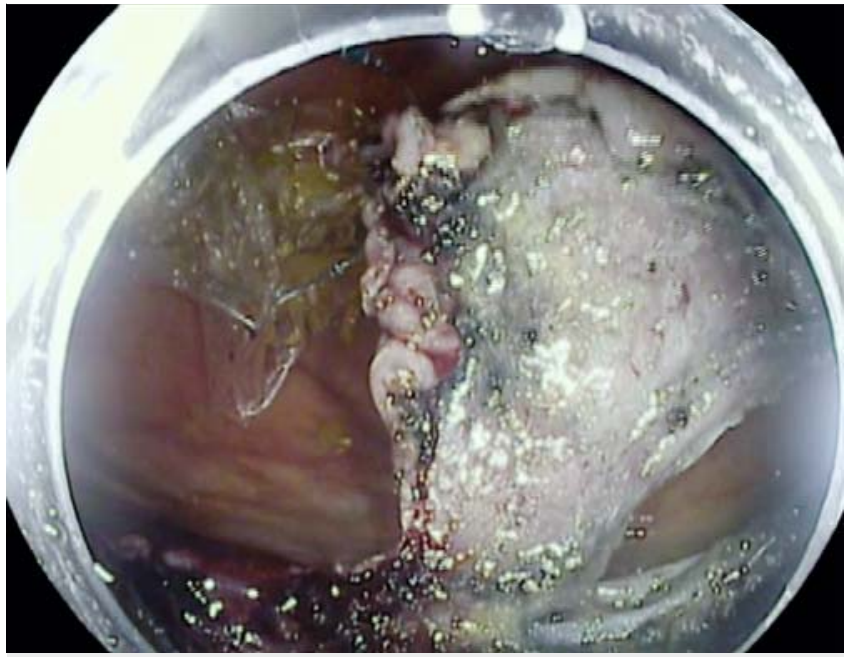

- Fig.4 Dynamic retraction is used for submucosal dissection.

ESD using the device in an animal model for a total of five procedures in two training sessions. Then, we started to perform ESD using DEIP at Baylor College of Medicine. Two DEIP procedures were performed in 2017. In 2018, 17 colonic lesions were removed with a standard colonic ESD approach versus five lesions removed with DEIP. In 2019, 14 colonic lesions were removed with a standard ESD approach and 53 lesions were removed by DEIP. The choice between the approaches was left to the endoscopist's preference based on the availability of the device or endoscopy staff familiar with operating the device at the time of the procedure.

For standard ESD, a transparent plastic cap (Disposable Distal Attachment, Model D-201-15004; Olympus America Inc., Center Valley, Pennsylvania, United States) was fitted to the distal end of the colonoscope. For DEIP, a U.S. Food and Drug Administration-approved commercially available double-balloon endoluminal intervention platform (DiLumen, Lumendi, Westport, Connecticut, United States) was used. This platform comprises a flexible sheath with two independently inflatable balloons (fore and aft balloons). The endoscope passes through the sheath using a gel lubricant with a $1-\mathrm{cm}$ endoscope tip projecting out of the sheath. Endoscope tip stability is ensured by the aft balloon, while flattening of the mucosal folds with lesion retraction is provided by the fore balloon [8].

Submucosal injection of compound solution composed of 500 CC of HESPAN (6\% hetastarch in $0.9 \%$ sodium chloride), 1 cc of epinephrine, $1: 10,000,0.1 \mathrm{mg} / \mathrm{mL}$, and 3 cc of methylene blue $(1: 20000 \mathrm{~mL})$ was used to lift the lesion-bearing mucosa. Incision of three-quarters of the circumference with a DualKnife (Olympus America Inc., Center Valley, Pennsylvania, United States) to reach the submucosal plane of dissection was then performed to allow adequate retention of the submucosal injectate. The incision was performed using Endocut $\mathrm{Q}$ mode $(3,3,3)$ of Erbe VIO 200 s generator (Erbe USA Marietta, Georgia, United States). After identification of the submucosal plane, repeated injection and dissection was performed using Swift Coag mode (Effect 3, watt: 35) followed by completing the circumferential incision to ensure resection of the lesion in one-piece fashion (en bloc resection method). Whenever needed, carbon dioxide insufflation was done using a $\mathrm{CO}_{2}$ EFFICIENT Endoscopic Insufflator STERIS (Mentor, Ohio, United States). For hybrid ESD, a snare was used for the final resection step after performing partial submucosal dissection with the DualKnife (Olympus America, Center Valley, Pennsylvania, United States) using dry cut current and swift coagulation mode for dissection. A coagulation grasper (Olympus America, Center Valley, Pennsylvania, United States) was used to control intraprocedural bleeding. After the resection was completed, the lesion was extracted and mounted over cardboard with small pins with careful examination of the lesion's border. The decision to resort to hybrid ESD was made by the operator (M.O.). Reasons for switching to hybrid ESD were: 1) lack of traction of the dissected part of the lesion; 2 ) inability to stabilize the endoscope with respect to target lesion to allow sufficient dissection and 3 ) expediting the procedure in case of micro-perforation or hemodynamic instability.

Study variables collected were patient age, gender, body mass index (BMI), size and location of the lesion, successful completion of en bloc and curative resection (yes/no), histopathological examination of the lesion, and ESD operative and postoperative complications.

\section{Study outcomes}

En bloc resection was defined as resection of the polyp in a onepiece fashion with macroscopic tumor-free margins. R0 resection was defined as specimens with negative deep and lateral resection margins for adenoma/cancer. Curative resection was defined as en bloc, R0 resection of colon polyp with $<1000 \mu \mathrm{m}$ of submucosal invasion and favorable histologic features [11]. Unfavorable histologic features were defined by Rex et al. as: 1) margin between the tumor and cautery line $<2 \mathrm{~mm}$; 2) invasion of the stalk; 3) poor differentiation; 4) lymphovascular invasion; and 5) inadequate orientation of the histologic sections for pedunculated lesions. For nonpedunculated lesions, unfavorable histologic features were defined as: 1 ) piecemeal resection; 2) positive resection margins; 3 ) invasion depth $>1000$ $\mu \mathrm{m} ; 4)$ poor differentiation; 5) lymphovascular invasion; 6) tumor budding; and 7) inadequate orientation of the histologic sections [11].

Procedure time was defined as the time interval from scope insertion to withdrawal. Operative complication was defined as micro-perforation recognized during the ESD procedure. Postoperative complications were defined as: 1 ) abdominal pain necessitating healthcare provider visit or hospital admission; 2) bleeding that required blood transfusion or emergency endoscopic management; and 3 ) perforation evident on abdominal imaging ( $\mathrm{x}$-ray or computed tomography) after the ESD procedure.

\section{Statistical analysis}

Baseline demographics and operative characteristics were described as mean $( \pm S D)$. Characteristics were compared using the chi-square test and student's $t$-test. $P<0.05$ was considered statistically significant. 


\section{Results}

\section{Procedures characteristics}

Our study cohort included 111 patients who underwent colonic ESD with 51 standard ESD cases and 60 DEIP cases. The mean $( \pm S D)$ age for the standard ESD group was 66.3 years $( \pm 10.7)$ compared with 65.5 years $( \pm 10.8)$ in the DEIP group. There were more females (54.9\%) in the standard ESD group, while there were more males (53.3\%) in DEIP group. Mean ( \pm SD) BMI was $28.0 \mathrm{~kg} / \mathrm{m}^{2}( \pm 4.4)$ in the standard ESD group compared with $29.3 \mathrm{~kg} / \mathrm{m}^{2}( \pm 6.2)$ in the DEIP group. Among the standard ESD group, $72.5 \%$ of lesions were in the right colon and $27.5 \%$ of lesions in the left colon with mean $( \pm S D)$ lesion size of $6.2 \mathrm{~cm}^{2}( \pm$ 5.5). Among the DEIP group, $81.7 \%$ of lesions located in the right colon and $18.3 \%$ of lesions located in the left colon with mean $( \pm S D)$ lesion size of $7.6 \mathrm{~cm}^{2}( \pm 6.0)$. There were no significant differences in age, gender, BMI, tumor location, or size between the two groups ( $\triangleright$ Table 1 ).

- Table 1 Baseline characteristics of the study population according to assisted ESD.

\begin{tabular}{|c|c|c|c|}
\hline \multirow[b]{2}{*}{ Characteristic } & \multicolumn{2}{|l|}{ Number (\%) } & \multirow[b]{2}{*}{$P$ value } \\
\hline & $\begin{array}{l}\text { Standard } \\
\text { ESD }(n=51)\end{array}$ & $\begin{array}{l}\text { DEIP } \\
(n=60)\end{array}$ & \\
\hline $\begin{array}{l}\text { Mean }( \pm S D) \text { age at ESD, } \\
\text { years }\end{array}$ & $66.3 \pm 10.7$ & $65.5 \pm 10.8$ & .7 \\
\hline - Male & $23(45.1)$ & $32(53.3)$ & \multirow[t]{2}{*}{.4} \\
\hline - Female & $28(54.9)$ & $28(46.7)$ & \\
\hline - Mean ( \pm SD) BMI & $28.0 \pm 4.4$ & $29.3 \pm 6.2$ & .2 \\
\hline $\begin{array}{l}\text { - Mean }( \pm S D) \text { size of } \\
\text { lesion, } \mathrm{cm}^{2}\end{array}$ & $6.2 \pm 5.5$ & $7.6 \pm 6.0$ & .2 \\
\hline \multicolumn{3}{|l|}{ Histopathology } & \multirow[t]{9}{*}{.4} \\
\hline - Adenoma (tubular) & $22(43.1)$ & $33(55.0)$ & \\
\hline $\begin{array}{l}\text { - Tubulovillous and } \\
\text { villous adenoma }\end{array}$ & $5(9.8)$ & $5(8.3)$ & \\
\hline $\begin{array}{l}\text { - Polyp with high-grade } \\
\text { dysplasia }\end{array}$ & $6(11.8)$ & $7(11.7)$ & \\
\hline $\begin{array}{l}\text { - Adenocarcinoma T1 } \\
\text { mucosa }\end{array}$ & $2(3.9)$ & $1(1.7)$ & \\
\hline $\begin{array}{l}\text { - Adenocarcinoma T1 } \\
\text { submucosa }\end{array}$ & $2(3.9)$ & $2(3.3)$ & \\
\hline $\begin{array}{l}\text { - Sessile serrated } \\
\text { adenoma }\end{array}$ & $8(15.7)$ & $10(16.7)$ & \\
\hline - Hyperplastic & 0 & $1(1.7)$ & \\
\hline - Other & $6(11)$ & $1(1.7)$ & \\
\hline \multicolumn{3}{|l|}{ Location of lesion } & \multirow[t]{3}{*}{.3} \\
\hline - Right colon & $37(72.5)$ & $49(81.7)$ & \\
\hline - Left colon & $14(27.5)$ & $11(18.3)$ & \\
\hline
\end{tabular}

\section{Study outcomes}

Mean $( \pm S D)$ procedure times were 81.9 minutes $( \pm 35.4)$ and 96.4 minutes $( \pm 42.2)$ in standard ESD and DEIP groups, respectively ( $\triangleright$ Table 2 ). Hybrid ESD was performed in $51.0 \%$ and 36.7 $\%$ of patients in the standard ESD and DEIP groups, respectively, $P=.2$. The en bloc resection rate was similar between the two groups with $76.5 \%$ and $78.3 \%$ in standard ESD and DEIP groups, respectively, $P=.08$. The curative resection rates was also similar between the two groups, with $68.6 \%$ for standard ESD compared with $70.0 \%$ for DEIP, $P=1$.

Regarding complications, micro-perforation was encountered in one patient $(1.7 \%)$ in the DEIP group and was successfully managed with clip closure during the procedure. Post-ESD abdominal pain was encountered in $3.9 \%$ of patients in the standard ESD group compared with $5.0 \%$ of patients in the DEIP group. Postoperative bleeding was found in $5.9 \%$ of patients in standard ESD group. However, no patients in the DEIP group suffered postoperative bleeding.

To assess for improvement in procedure time in the DEIP group overtime, we divided DEIP cases into two groups (first half and second half). The mean $( \pm S D)$ procedure time in the first half was 99.4 minutes $( \pm 43.6)$ compared with 93.5 minutes $( \pm 41.4)$ in the second half, $P=0.6$.

\section{Secondary analysis based on hybrid ESD status}

We reclassified all patients according to hybrid ESD status. The hybrid ESD group included 48 patients, while the non-hybrid ESD group included 63 patients. Age, gender, BMI, tumor location and size, procedure time, curative resection, operative, and

Table 2 Study outcomes according to assisted ESD.

\begin{tabular}{|c|c|c|c|}
\hline \multirow[b]{2}{*}{ Outcome } & \multicolumn{2}{|l|}{ Number (\%) } & \multirow[b]{2}{*}{$P$ value } \\
\hline & $\begin{array}{l}\text { Standard } \\
\text { ESD }(n=51)\end{array}$ & $\begin{array}{l}\text { DEIP } \\
(n=60)\end{array}$ & \\
\hline $\begin{array}{l}\text { Mean }( \pm S D) \text { procedure } \\
\text { time, minutes }\end{array}$ & $81.9 \pm 35.4$ & $96.4 \pm 42.2$ & .06 \\
\hline \multicolumn{3}{|c|}{ Post-operative complications } & \multirow[t]{5}{*}{.2} \\
\hline - No & $46(90.2)$ & $56(93.3)$ & \\
\hline - Abdominal pain & $2(3.9)$ & $3(5.0)$ & \\
\hline - Bleeding & $3(5.9)$ & 0 & \\
\hline - Perforation & 0 & $1(1.7)$ & \\
\hline \multicolumn{3}{|c|}{ ESD operative complications } & \multirow[t]{3}{*}{1} \\
\hline - No & $51(100.0)$ & $59(98.3)$ & \\
\hline - Micro-perforation & 0 & $1(1.7)$ & \\
\hline - En bloc resection & $39(76.5)$ & $47(78.3)$ & .8 \\
\hline - Curative resection & $35(68.6)$ & $42(70.0)$ & 1 \\
\hline - Hybrid ESD & $26(51.0)$ & $22(36.7)$ & .2 \\
\hline
\end{tabular}

ESD, endoscopic submucosal dissection; DEIP, double-balloon endoluminal intervention platform. 
postoperative complications were comparable between the two groups ( $\triangleright$ Table $3, \triangleright$ Table 4). The rate of en bloc resection was significantly higher in the non-hybrid ESD group (88.9\%) compared to the hybrid ESD group (62.5\%), $P=0.001$.

\section{Non-hybrid ESD}

- Table 5 shows study outcomes between the standard ESD and DEIP groups after exclusion of hybrid ESD from both groups. Study outcomes were comparable between the two groups. En bloc resection was higher in the DEIP group (92.1\%) compared with standard ESD group (83.3\%), but not statistically significant, $P=0.4$.

\section{Discussion}

This study demonstrated a similar procedure time, en bloc and curative resection rates between DEIP and standard ESD. There is a lower chance of switching to hybrid ESD in the DEIP group, though the difference did not reach statistical significance. Non-hybrid ESD had a significantly higher en bloc resection rate compared with hybrid ESD. These data underscore the importance of DEIP in decreasing the chance of switching to hybrid ESD, which in turn increases the en bloc resection rate in complex colon polyps and accordingly, the local recurrence rate [12]. En bloc resection is the goal of every ESD procedure, ensuring the removal of colonic polyps with tumor-free margins and higher rates of curative resection [13].

ESD is a technically challenging and time-consuming procedure, necessitating ongoing innovations to overcome its complexity. DEIP has emerged as a new tool to ease the challenging nature of ESD through counter-traction to expose the dissection field. However, published data are scare as it is a newly developed platform [8]. Our experience revealed the importance of DEIP in straightening the mucosa around colonic polyps, especially in redundant intestinal segments and anatomically difficult and poorly visualized lesions. We believe such factors constitute a major share of the ESD procedure complexity. One of the specific limitations of colonic ESD is the ability to obtain a stable position, which allows steady submucosal dissection. Pocket-creation ESD was proposed as a solution to the instability associated with colonic ESD. In a study of 887 colonic lesions treated by ESD, the pocket-creation method (PCM) was associated with higher en bloc (100\%) and R0 Resection rates (91\%) compared with standard ESD [14]. DEIP provides the stability required to perform ESD without the need for creating a pocket, which may require greater expertise in certain locations such as lesions behind folds or in fibrotic lesions. Dynamic retraction using a clip to attach the dissected distal lesion margin to a suture mounted on the fore balloon of the device was crucial in expediting dissection in fibrotic cases and large lesions ( $\triangleright$ Video 1 ).

No added benefit of DEIP vs. standard ESD regarding procedure time was observed in our study. This was attributed to a longer time taken to inflate the fore and aft balloons to set up the tissue traction. Once the double-balloon endoluminal intervention platform is settled, dissection is easy to perform with improved visualization and mucosal stability.
Table 3 Characteristics of the study population according to hybridESD.

\begin{tabular}{|c|c|c|c|}
\hline \multirow[b]{2}{*}{ Characteristic } & \multicolumn{2}{|l|}{ Number (\%) } & \multirow[b]{2}{*}{$P$ value } \\
\hline & $\begin{array}{l}\text { Non-hybrid } \\
\text { ESD }(n=63)\end{array}$ & $\begin{array}{l}\text { Hybrid-ESD } \\
(n=48)\end{array}$ & \\
\hline $\begin{array}{l}\text { Mean }( \pm S D) \text { age at ESD, } \\
\text { years }\end{array}$ & $65.8 \pm 11.9$ & $65.9 \pm 9.2$ & .2 \\
\hline - Male & $28(44.4)$ & $27(56.3)$ & \multirow[t]{2}{*}{.2} \\
\hline - Female & $35(55.6)$ & $21(43.8)$ & \\
\hline - Mean $( \pm S D)$ BMI & $28.7 \pm 6.3$ & $28.7 \pm 4.2$ & .1 \\
\hline $\begin{array}{l}\text { - Mean }( \pm \mathrm{SD}) \text { size of } \\
\text { lesion, } \mathrm{cm}^{2}\end{array}$ & $7.5 \pm 6.1$ & $6.2 \pm 5.4$ & .4 \\
\hline \multicolumn{3}{|l|}{ Location of lesion } & \multirow[t]{3}{*}{.3} \\
\hline - Right colon & $46(73.0)$ & $40(83.3)$ & \\
\hline - Left colon & $17(27.0)$ & $8(16.7)$ & \\
\hline
\end{tabular}

- Table 4 Study outcomes for hybrid-ESD.

\begin{tabular}{|c|c|c|c|}
\hline \multirow[b]{2}{*}{ Outcome } & \multicolumn{2}{|l|}{ Number (\%) } & \multirow[b]{2}{*}{$P$ value } \\
\hline & $\begin{array}{l}\text { Non-hybrid } \\
\text { ESD }(n=63)\end{array}$ & $\begin{array}{l}\text { Hybrid-ESD } \\
(n=48)\end{array}$ & \\
\hline $\begin{array}{l}\text { Mean }( \pm S D) \text { procedure } \\
\text { time, minutes }\end{array}$ & $89.5 \pm 38.9$ & $90.5 \pm 41.3$ & .9 \\
\hline \multicolumn{3}{|c|}{ Postoperative complications } & \multirow[t]{5}{*}{.4} \\
\hline - No & $60(95.2)$ & $42(87.5)$ & \\
\hline - Abdominal pain & $2(3.2)$ & $3(6.3)$ & \\
\hline - Bleeding & $1(1.6)$ & $2(4.2)$ & \\
\hline - Perforation & 0 & $1(2.1)$ & \\
\hline \multicolumn{3}{|c|}{ ESD operative complications } & \multirow[t]{3}{*}{.4} \\
\hline - No & $63(100.0)$ & 47 (97.9) & \\
\hline - Micro-perforation & 0 & $1(2.1)$ & \\
\hline - En bloc resection & $56(88.9)$ & $30(62.5)$ & .001 \\
\hline - Curative resection & $43(68.3)$ & $34(70.8)$ & .8 \\
\hline
\end{tabular}

Regarding operative and postoperative complications, rates of abdominal pain and micro-perforation were slightly higher in DEIP compared with standard ESD. These could be explained by the counter-traction imposed on the submucosal tissue by the double-balloon endoluminal intervention platform exposing the vulnerable muscle layer to micro-perforation during dissection [8]. Moreover, post-ESD electrocoagulation syndrome may be the underlying cause for abdominal pain after the procedure [15]. 
- Table 5 Study outcomes for standard ESD and DEIP after exclusion of hybrid ESD.

\begin{tabular}{|c|c|c|c|}
\hline \multirow[b]{2}{*}{ Outcome } & \multicolumn{2}{|l|}{ Number (\%) } & \multirow[b]{2}{*}{$P$ value } \\
\hline & $\begin{array}{l}\text { Standard ESD } \\
(n=24)\end{array}$ & $\begin{array}{l}\text { DEIP }(n= \\
38)\end{array}$ & \\
\hline $\begin{array}{l}\text { Mean }( \pm S D) \text { procedure } \\
\text { time, minutes }\end{array}$ & $82.6 \pm 36.9$ & $93.8 \pm 39.9$ & .3 \\
\hline \multicolumn{3}{|c|}{ Postoperative complications } & \multirow[t]{5}{*}{.2} \\
\hline - No & $23(95.8)$ & $36(94.7)$ & \\
\hline - Abdominal pain & 0 & $2(5.3)$ & \\
\hline - Bleeding & $1(4.2)$ & 0 & \\
\hline - Perforation & 0 & 0 & \\
\hline \multicolumn{3}{|c|}{ ESD operative complications } & \multirow[t]{3}{*}{-} \\
\hline - No & $24(100.0)$ & $38(100.0)$ & \\
\hline - Micro-perforation & 0 & 0 & \\
\hline - En bloc resection & $20(83.3)$ & $35(92.1)$ & .4 \\
\hline - Curative resection & $16(66.7)$ & $26(68.4)$ & 1 \\
\hline
\end{tabular}

ESD, endoscopic submucosal dissection; DEIP, double-balloon endoluminal intervention platform.

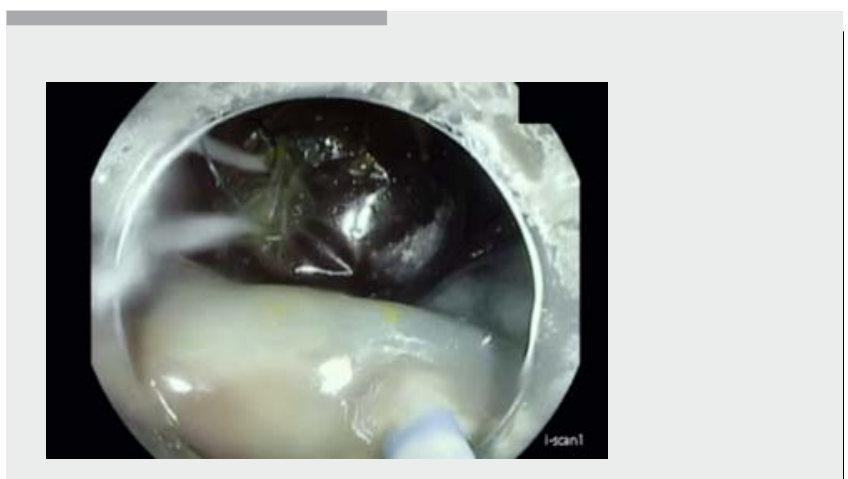

Video 1 Sessile serrated adenoma with severe fibrosis due to prior EMR and tattooing removed with DEIP using dynamic retraction method.

In a Japanese retrospective study, the en bloc resection rate was lower in hybrid ESD compared with non-hybrid ESD at $66.7 \%$ and $94.2 \%$, respectively [6]. The Japanese en bloc resection rates were slightly higher than our results $(62.5 \%$ in hybrid ESD and $88.9 \%$ in non-hybrid ESD). Our outcomes were lower compared with the Japanese outcomes. The difference could be explained by a steep learning curve for colonic ESD, high $\mathrm{BMI}$ in our populations making colonoscopy and endoscopic dissection more challenging, and the high prevalence of fibrosis in referred lesions in the west due to aggressive sampling, tattooing directly under the lesions or attempts that resulted in incomplete polypectomies. On the other hand, our procedure time was shorter than in the Japanese study for non-hybrid ESD. The above-mentioned Japanese cohort procedure time for non-hybrid ESD was 122 minutes $( \pm 72.2$ ) compared with 89.5 minutes $( \pm 38.9)$ in our study. They defined procedure time from first mucosal incision to completion of hemostatic treatment after submucosal dissection. However, we defined the procedure time from scope insertion to withdrawal. It is worth mentioning that hybrid ESD was carried out as a rescue procedure in long ESD procedures with inadequate dissection, resulting in lower rates of en bloc resection [6].

Our study has limitations associated with being retrospective and non-randomized. Potential bias may be present given the preference for DEIP in overweight and obese patients, anatomically challenging polyps, and patients with a history of difficult colonoscopies due to redundant intestinal segments. This study is the first to report resection outcomes in patients who have undergone DEIP compared with standard ESD. It is worth mentioning that DEIP is associated with a higher cost for ESD. However, DEIP could become cost-effective if it enables the endoscopist to perform ESD safely and decreases the number of referrals for surgical resection of colon polyps. Further data are needed on the cost-effectiveness of this novel device.

\section{Conclusion}

In conclusion, similar procedure time, en bloc and curative resection rates were observed in both the DEIP and standard ESD groups. The odds of switching to hybrid ESD in DEIP were lower compared to standard ESD. The introduction of DEIP may create a unique opportunity for reducing the complexity of ESD and encouraging its widespread use. A multicenter, randomized, controlled trial is needed to demonstrate impactful outcomes with DEIP.

\section{Competing interests}

Dr. Othman is a consultant for Olympus, Boston Scientific, Conmed, Abbvie and Lumendi. Dr. Othman is a consultant and an advisory board member for Lumendi. Baylor College of Medicine represented by Dr. Othman as principal investigator received a research grant $(\$ 50,000)$ to establish a colonic ESD registry for patients treated with DIEP. The current manuscript is investigator-initiated research that is not funded by Lumendi. Lumendi did not provide any support for generating this manuscript and no Lumendi employees or agents were involved in the manuscript preparation.

\section{References}

[1] Repici A, Hassan C, De Paula Pessoa D et al. Efficacy and safety of endoscopic submucosal dissection for colorectal neoplasia: A systematic review. Endoscopy 2012; 44: 137-150

[2] Bhatt A, Abe S, Kumaravel A et al. Indications and techniques for endoscopic submucosal dissection. Am J Gastroenterol 2015; 110: 784-791

[3] Longcroft-Wheaton G, Bhandari M, Alkandari A et al. Recent advances in the management of large and complex colonic polyps. F1000Research 2018: 7

[4] Yoshida N, Yagi N, Naito Y et al. Safe procedure in endoscopic submucosal dissection for colorectal tumors focused on preventing complications. World J Gastroenterol 2010; 16: 1688-1695 
[5] Bae JH, Yang DH, Lee S et al. Optimized hybrid endoscopic submucosal dissection for colorectal tumors: A randomized controlled trial. Gastrointest Endosc 2016; 83: 584-592

[6] Okamoto K, Muguruma N, Kagemoto K et al. Efficacy of hybrid endoscopic submucosal dissection (ESD) as a rescue treatment in difficult colorectal ESD cases. Dig Endosc 2017; 29: 45-52

[7] Draganov PV, Gotoda T, Chavalitdhamrong D et al. Techniques of endoscopic submucosal dissection: Application for the Western endoscopist? Gastrointest Endosc 2013; 78: 677-688

[8] Sharma S, Momose K, Hara $\mathrm{H}$ et al. Facilitating endoscopic submucosal dissection: double-balloon endolumenal platform significantly improves dissection time compared with conventional technique (with video). Surg Endosc 2019; 33: 315-321

[9] Sharma S, Hiratsuka T, Hara H et al. Antigravity ESD - double-balloonassisted underwater with traction hybrid technique. Endosc Int Open 2018; 06: E739-E744

[10] Jacques ], Albouys J, Guyot A et al. Endoscopic submucosal dissection of a laterally spreading tumor in the right colon with a gastroscope after shortening the colon using a new double-balloon platform. Endoscopy 2019; 51: E364-E365

[11] Rex DK, Shaukat A, Wallace MB. Optimal management of malignant polyps, from endoscopic assessment and resection to decisions about surgery. Clin Gastroenterol Hepatol 2019; 17: 1428-1437

[12] Saito $Y$, Uraoka T, Yamaguchi $Y$ et al. A prospective, multicenter study of 1111 colorectal endoscopic submucosal dissections (with video). Gastrointest Endosc 2010; 72: 1217-1225

[13] Fujiya M, Tanaka K, Dokoshi T et al. Efficacy and adverse events of emr and endoscopic submucosal dissection for the treatment of colon neoplasms: A meta-analysis of studies comparing emr and endoscopic submucosal dissection. Gastrointest Endosc 2015; 81: 583595

[14] Takezawa T, Hayashi Y, Shinozaki S et al. The pocket-creation method facilitates colonic endoscopic submucosal dissection (with video). Gastrointest Endosc 2019; 89: 1045-1053

[15] Jung D, Youn YH, Jahng J et al. Risk of electrocoagulation syndrome after endoscopic submucosal dissection in the colon and rectum. Endoscopy 2013; 45: 714-717 